\title{
A Research on English Translation of Public Signs in Shanxi Province-Based on Three-dimension in Eco-translatology
}

\author{
Zhaodong Zeng \\ School of Foreign Languages, Shanxi Normal University, Linfen, 041000, China
}

\begin{abstract}
As Shanixi province enjoys rich tourist attractions, there are many problems in English version of public signs in tourism attractions, like mistakes in English usage, unreasonable pragmatic function, obscure cultural transmission and unidiomatic expressions. Based on eco-translatology put forward by Hu Gengshen, the article seeks to explore how to standardize the translation of public signs in Shanxi tourist attractions with linguistic dimension, cultural dimension and communicative dimension and to give some strategies and advice to promote its tourism development.
\end{abstract}

Index Terms - eco-translatology, tourist attractions in Shanxi, English translation of public signs, translation studies

\section{INTRODUCTION}

Shanxi province of north China is blessed with rich tourism resources while its tourism develops at a slow pace. As the Belt and Road Initiative presses ahead, an ever increasing number of foreign tourists flood into China to visit inviting and exotic scenery in China and learn about Chinese culture. That promises an exciting opportunity and an enabling climate for Shanxi's tourism growth. The introduction and marketing event for Shanxi province was held by Chinese Ministry of Foreign Affairs in Beijing on February 25, 2019. As part of its efforts of responding to this event, Shanxi has to improve its public sign translation in tourist attractions, which plays an indispensable role in introducing Shanxi to the rest of the world. Translation of public signs can not only serve as a mirror of the quality and level of tourism services in Shanxi province tourist attractions, but also make a great difference to publicity image of Shanxi and even China. However, tourist attractions in Shanxi province are confronted with a great deal of various problems in English translation. Rare researches and studies from the perspective of ecological translation have been conducted by scholars in the past years to probe into the English translation of public signs in tourist attractions in Shanxi province. This paper, on the basis of ecological translation put foeward by Professor Hu Gengshen as theoretical framework, seeks to analyze the problems in English translation in Shanxi tourist attractions from three dimensions of linguistic dimension, cultural dimension and communicative dimension. The paper will come up with some relevant translation strategies and solutions and try to provide a new perspective for English translation of public signs in Shanxi tourist attractions as part of endeavors to push forward the tourism growth in Shanxi province and make Shanxi's development driven more by its tourism sector.

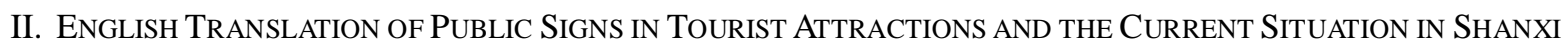 TOURIST ATTRACTIONS}

Tourism translation is a type of translation (practice) for tourism activities, tourism specialty and tourism industry and an interactive activity typical of trans-language, trans-society, trans-times-and-space, trans-culture and trans-emotion features. Tourism translation involves many kinds of texts and is applied frequently, highly practical and lively in style (Chen Gang, 2014). There are many tourism materials, for instance, illustrative handbook, map, public signs, commentary of tour guides and so forth. The purpose of tourism translation is to convey to foreign tourists the cultural information of a certain region in an accurate and friendly way. When it comes to tourism translation, if the translator does not take different cultural factors into serious consideration and yet simply transform the literal meanings of texts in two languages, then the purpose of tourism translation will, if any, be far difficult to be achieved. Beyond that, some unnecessary mistakes and misunderstandings will get in the way and take a toll on publicity image.

Public signs in tourist attractions mainly refer to various texts, graphs, signs and relevant information, for example, introduction texts about scenic spots, guideposts in and outside scenic spots,signs of public facilities and services, rules and regulations for tourists and other types of materials of warning and prompt related to tourism services (Yang Beiyi, 2018). As an integral part of tourism attractions, public signs has the capabilities to direct and prompt tourists and provide tourists with accurate and clear guiding and cultural information. That means, on the one hand, English translation of public signs in tourist attractions needs to be standard and accurate and conform to the expression habits of target language. On the other hand, it is indispensable to add some related cultural information in order to promote 
Chinese culture and customs and help foreign tourists get a better understanding of Chinese culture.

There is a popular saying, "if you want to learn about China in the past century, you would better observe Shanghai; if in the past one thousand years, Xi' an, the capital city of Shaanxi province of north China; if in the past five thousand years, Shanxi province," which vividly highlights that Shanxi province enjoys a time-honored history. Shanxi is not only home to a sea of natural landscape but also a flood of time-honored cultural tourism attractions. It enjoys a great number of national 5A tourist attractions such as Wutai Mountain known as "a holy place for Buddhism ", Yungang Grottoes, one of four great grottoes in China, best-preserved Pingyao ancient city, Royal Prime Minister's Palace and Qiao's Grand Courtyard as well as Heng Mountain and Xuankong Temple and so on. Some of those tourist attractions have both inviting natural landscape and profound Chinese traditional culture and thoughts. English translation of public signs in tourist attractions features prominently in introducing these tourism places to foreign tourists and attracting them. Excellent public signs can fully exhibit Shanxi's distinct culture. However, the situation of English version of public signs in Shanxi is anemic as there are various problems in translating. Public signs fail to attract tourists and promote its culture, and even worse, may bring out some misunderstandings for foreign tourists, causing a bad impact on the sustainable and healthy development of Shanxi tourism economy and the publicity image of Shanxi province.

\section{A. Mistakes in Vocabulary and Grammar}

Some basic problems in tourist attractions are misspelling of words, wrong use of single and plural form of nouns and incorrect grammatical usage in sentence structure. In an introduction text of figure of Buddha in Yungang Grottoes, there are some mistakes of misspelling. The original text is “释迦牟尼佛像，高 15.5 米，北墙......”, and its English version is "The sakyamuni buddhs, 15.5 metres high on the north wall....." (Liu Hongqing, Xu Jing, 2016). In terms of the meaning the Chinese text tries to convey, "buddhs" are misspelled in English version. It should have been the plural form "buddhas". Thus after the correction, it is "The sakyamuni buddhas, 15.5 metres high on the north wall......". In the website of Yungang Grottoes for external propaganda, a sentence says "Cave 1 and Cave 2 from a pair of Buddhist cave temples". It is obvious that "form" is misspelled and it should be corrected as "from". These two words look similar in their spelling but have totally different usages and meanings. Accurate grammar of target language is the foundation of conveying semantic meaning. The phrase "Please entrance" in some entrances of Yungang Grottoes falls under the category of incorrect grammatical use. The word "entrance" is a noun and "please" must be followed by a verb rather than a noun. The phrase can be translated into "Entrance".

\section{B. Confusion in English Translation}

There are different translation versions of the same tourism spot in many tourist attractions of Shanxi, which may confuse foreign tourists. Some public signs and names of target language in public space are of different types and not standardized. For instance, there exist various English versions of restroom in Yungang Grottoes, as some are translated into "W.C.", which is clearly out of date, some are "washroom " an some others are "man, woman ". Anyway there is no standardized and unified English version of “则所” or “卫生间” in Chinese. In fact, men's and women's restrooms can be respectively translated into " male" and "female", and indoor restrooms and outdoor restrooms can be respectively standardized as "toilet" and "washroom ". Beyond that, some scenic spots do not have unified names of target language. “五台山” has different translation versions like “Wutai Mountain、The Wutai Mountain、Mount Wutai、 Mt. Wutai”. In Wutai Mountain, “释迦牟尼” also has different translation versions as some are translated in the way of Chinese Pinyin , some are translated in Sanskrit and some others are translated in English. But the correct name should be "Sakyamuni". As for “罗汉” and “菩萨”, there are even more translation versions, the one and only standardized and accurate English name are respectively “ Bodhisattva” and “Arahat” (Li Ertao, 2010).

\section{Dysfunction of Public Signs of Target Language}

The function of public signs is to direct, guide and warn tourists to achieve some certain purposes. Weakening, strengthening or obscuring the function of public signs make it possible that tourists receive unreasonable emotional expressions, misunderstand the information provided by public signs and feel stressed. In Pingyao Ancient City of Shanxi province, on one old hall reads a sentence, “大堂照相取景收费” and its English version is “Collecting Fees of Taking Photos in the Court". In this English version, the actor of the verb "collect" is ambiguous, which fails to reach the goal of conveying correct information as foreign tourists get confused about who exactly collects fees, photo takers or others. It can be translated into "We would charge for taking photos in the court". In Jin Temple Garden of Taiyuan City, beside the lake reads a Chinese sentence “请爱护水源” and it is translated into “ Please Don't Pollute the Water". Here the translation is rigid in its tone and foreign tourists may assume that Chinese people think they would have the intention of deliberately polluting water. That may lead to misunderstanding and unpleasure to foreign tourists. It can be translated into "Please Keep the Water Clean".

\section{The BASIC CONNOTATION OF ECO-TRANSLATOLOGY}

Eco-translatology is a translation theory put forward by Chinese scholar Hu Gengshen on the basis of "adaptive 
selection theory" of Charles Darwin and represents the original translation theory with Chinese indigenous distinctive features that Chinese scholars have offered for the first time (Chen Jinlian, 2015). Eco-translatology is a interdisciplinary translation theory that integrates ecology with translation. Eco-translatology is both a "metaphor" and a "notional reference". The former means that it represents an integral study that conducts a metaphorical analogy between translational ecology and natural ecology, while the latter means that it tends to depend on the inter-relationship between the translator and the translational ecological environment, especially the research on the translator's living situation and ability development in the translation process (Hu Gengshen, 2008). Eco-translatology emphasizes the translator as the center and argues that translation means adaptive selection. It puts forward brand new concepts and descriptions of nature of translation, translational eco-environment, translation process, translation principle, translation method and assessment standard. From the perspective of Eco-translatology, nature of translation is "the selective activity of the translator adapting to translational eco-environment". It emphasizes two aspects of translation process: one is that the translator seeks to adapt to the eco-environment of original texts with original texts as the typically prominent component; the other one is that the translator "makes choices" of the translation text with the translator as the typically prominent component after completely adapting. Translational eco-environment refers to the world where the original text, language and target language stay. In other words, it is seen as a whole where language, communication, culture, society, writer, reader and agent are interrelated (Hu Gengshen, 2008). Translation principle can be generalized as "multi-dimensional adaption and adaptive selection". Translation method means that the translator conducts "three-dimensional transformation" in the translation process, including linguistic dimension, cultural dimension and communicative dimension and the translator needs to do the transformation of various degrees between source language and target language from multiple dimensions. This paper will employ "three-dimensional transformation" translation method to analyze the problems in English translation of public signs in tourist attractions of Shanxi province.

\section{STRATEGIES FOR ENGLish VERSION OF PUbLIC SignS IN SHANXI}

As far as Eco-translatology is concerned, the nature of translation is " the selective activity of the translator adapting to translational eco-environment ", which means the translator's adaption to the eco-environment of source language and his or her selection of target language after adaptation. In the translation process, the translator needs to do the transformation between two languages from linguistic dimension, cultural dimension and communicative dimension, which is the translation method in eco-translatology. In a general sense, the higher a translation work's degree of "multi-dimensional adaptation" and "adaptive selection" is, the higher its " degree of holistic adaptation and selection" is (Hu Gengshen, 2018, p.4). Therefore, the translator is required to make the highest "degree of holistic adaptation and selection" to the best of his or her ability. As Shanxi province boasts various types of human and natural landscape with distinct features, the translation of public signs features prominently in appealing to foreign tourists and promoting charming Shanxi culture. This paper will, from the perspective of three dimension of eco-translatology, analyze problems in English translation of public signs in Shanxi tourist attractions and offer some recommendations for improvement and some translation strategies with the eco-environment of Shanxi taken into full consideration.

\section{A. Linguistic Transformation}

Professor Hu Gengshen holds the view that the adaptive transformation from the linguistic dimension is "the adaptive transformation of linguistic form in the translation process". English and Chinese are quite different in expression form, style and rules of use. Chinese focuses on " integration of meaning " while English " coordination of form "; Chinese features its frequent use of short clauses whose meanings are connected through internal relation, while in English, meanings of clauses are connected through conjunctions, prepositions and the like as a way of constructing a complete sentence. In eco-translatology, making translation text adapt to linguistic dimension means the adaptive transformation of linguistic form in the translation process. The transformation includes writing genre, wording and phrasing, sentence structure and language style (Chen Gang, 2004). That requires the translator should conform to the meaning of source language and not be restricted to the syntactic structure of source language when translating. The translator must convey the meaning that source text tries to express after the adaptive selection.

In the translation of public signs in Shanxi tourist attractions, the translator needs to fully comprehend the meaning of source text in order to ensure that the meaning of target language is consistent with that of source language. The translator needs to transform the source language by employing linguistic dimension strategy and make target language in accordance with its eco-translatology to form a smooth and proper text of target language. In Yungang Grottoes of Datong of north Shanxi, on one sign reads a sentence for introduction, “窟中上方开东、西两个明窗” and its translation is "On the upper part of each eastern and western walls is an opening used as a window". It is clear that there are two windows in Chinese text rather than the single form of " $a$ window" in English text. There stands an error between he meanings conveyed in Chinese and in English. This sentence can be translated into "On the upper part of each eastern and western walls are two openings used as windows" after the adaptive transformation of the translation text. In Wutai Mountain, a public sign says, “文化灿烂、古建成群、文物荟萃、珍品云集, 是中国古建、雕塑、绘画的艺术宝库” and its English version is " There are splendid cultures, ancient architectures and treasured relics and it is really the artistic legacy" (Chang Hua, 2011). In Chinese language, four-character idioms are frequently employed as they are 
readable and easy to be understood which are absent in English. That means the translator needs to select a translation text accordant with English expression forms and habits after completely understanding the meaning of source text and without being locked in the forms of source text. There are some synonymous expressions in the Chinese text such as “文物荟萃” and “珍品云集” that are partly deleted and integrated and then translated into “ treasured relics” to conform to the eco-environment of target language as English tends to avoid repetition.

The English version of public signs in Shanxi tourist attractions serves as a direct channel for introducing Shanxi culture to foreign tourists and a pivotal way of communication with them. From the perspective of eco-translatology, the meaning of English translation text must be consistent with that of the Chinese text. For that to happen, the translator is required to avoid misspelling, grammatical mistakes, semantic distortion and so forth, and to convey the meaning of source text in an accurate way. On top of that, the translator must conduct transformations of various degrees with the eco-environment of target language taken into full consideration and ensure that the translation text should be accordant with English expression habits and adaptive to the eco-environment.

\section{B. Cultural Transformation}

Eco-translatology thinks the adaptive transformation from the cultural dimension refers to "the translator focuses on the conveying and interpretation of cultural connotations of two languages in the translation process". That requires the translator should attach importance to the communication of cultures and thoughts between Chinese and English, ensure to convey thoughts of Chinese text to readers of target language and try not to lead to cultural misunderstanding and ideal conflicts. It is difficult for foreign tourists to understand Chinese culture given the great differences in histories and cultures between China and English-speaking countries. Therefore, the translator needs to be familiar with the culture of both source language and target language, which makes it possible to introduce to foreign tourists the unique culture of source language via translation. Foreign tourists who know little about scenic spots will not get a better understanding of and even hold misconceptions about distinctive regional cultures if the translator simply translates the literal meaning of public signs.

In Wutai Mountain, an introduction about Luohou Temple says, “始建于唐，明万历年间由太后李娘娘重建，清康 熙年间, 改黄庙 (由喇嘛主持)” and its English version is “It is found in Tang Dynasty and rebuilt by empress Li, the mother of emperor, in Wanli Period of Ming Dynasty. Later, it was changed to Yellow Temple (presidented over by Lamaists ) in Kangxi Period of Qing Dynasty" (Wang Yun, 2009). Firstly, in terms of grammar, "is found" should be corrected as "was founded" and "presidented" as "presided ". Secondly, from the cultural dimension, the English translation fails to help foreign tourists understand Buddhism culture in Wutai Mountain as some unfamiliar terms and names to them are not explained such as “唐”，“明万历年间”，“太后”, “清康熙年间” and “黄庙”. According to the eco-environment of ecotranslatology, the English translation needs to be transformed from the cultural dimension. Accordingly, necessary supplementary information is needed to explain the dynasties, for example, Tang Dynasty (A.D. 618-907), Wanli Period of Ming Dynasty (Wanli, A.D. 1572-1620, is the reign title of the emperor Zhu Yijun ), Kangxi Period of Qing Dynasty（Kangxi, A.D. 1662-1722, is the reign title of fourth emperor ). “Yellow temple”, “黄庙” in Chinese, refers to, which are absent in English translation and needed to explain. Therefore, the sentence can be translated into "it was changed to Yellow Temple, the temple of Tibetan Buddhism for lama" by adding necessary cultural information.

Nida believes that "one of the most important factors of determining the purpose of translation is recipients" and " texts are meaningful only when they are understood by recipients" (Zhu Yumin, 2015). When translating the public signs into English in Shanxi tourist attractions, the translator must fully understand and unmask the history and culture of source language behind the literal meaning. Meanwhile, the translator learns about the historical and cultural background of foreign tourists and then conducts the transformation from the cultural dimension. The English translation of public signs can not only communicate the cultural connotation of scenic spots but also be capable of triggering tourists' interests and appreciation.

\section{Communicative Transformation}

Eco-translatology argues that the adaptive transformation from the cultural dimension is "the adaptive transformation when the translator focuses on the communicative purpose of two languages in the translation process". The purpose of translation is not to simply convey information and culture by transforming source language into target language. The translator needs to build a connection between readers of target language and original texts and make them get superior feelings from translation texts as a way to achieve the purposes of source texts. The translator needs to make full use of all kinds of knowledge and information in her or his cognitive context to induce the communicative purpose behind the source text from different aspects like linguistic form and content, find out the optimal relevance between the information of source text and context setting and ultimately acquire the contextual effect of communication (Huang Dongqun, 2016). There will be a drop between the translation text and the expectation of readers of target language if the communicative purpose of the translation is ignored, making it difficult for readers of target language to accept the translation and causing the failure of communicative purpose.

In Pingyao Ancient City, some English translations of public signs that lack culture-dimensional adaptive 
transformation are incongruent with the eco-translatology of English. For example, one public sign reads, “不许随地吐 痰、大小便” " and it is translated into “Don't spit, piss and shit everywhere". This translation is far too colloquial and even a little bit vulgar as it fails to take into consideration the emotional factor and cultural background of English readers. It does not produce any communicative effect yet raises some doubt about Chinese ceremonies and spoils tourists' pleasure of travelling. For another instance, the public sign “闲人免进” in Yungang Grottoes is translated into "Admittance Denied to Idlers" which reads stiff and gives a unpleasant feeling. The translator can learn native expressions of foreign public signs in terms of such kind of English translation and acquaint herself or himself with English readers' expectation of translation. Here it can be translated into "Staff Only" which is readable and accordant with English communicative habits.

Public signs need to be effortless to be understood by foreign tourists and make tourists ready to cooperate in order to reach the purpose of communication. Therefore, when it comes to communicative dimension transformation, the translator must take into full consideration foreign tourists' communicative thinking pattern and cognitive habits and avoid making the translation rigid and stiff. In addition, the translator needs to be clear about the communicative purpose of source texts and foster an optimal context.

\section{CONCLUSION}

As the Belt and Road Initiative presses ahead, China is seeing a growing number of foreign tourists, which promises an exciting opportunity for the tourism development of Shanxi province. Meanwhile, Ministry of Foreign Affairs of China has held a global introduction and marketing event for Shanxi province as a way of pushing forward its transformation of development model. Such being the case, it is essential to study how to standardize the English translation of public signs in tourist attractions of Shanxi province as it serves as a "window" for foreign tourists to learn about Shanxi.

This paper, based on eco-translatology, employs the three-dimensional translation method to discuss and analyze some typical cases in the English translation of public signs of Shanxi tourist attractions. That is how this paper seeks to offer some suggestions and strategies for English translation of public signs and reach the psychological expectation of foreign tourists. This paper hopes to provide a new translation perspective to improve English translation in Shanxi province in a way that helps Shanxi fully exhibit and promote its culture and boost its cultural soft power.

\section{REFERENCES}

[1] Chang Hua. (2011). The English Translation Strategy of Tourism in the Holy Place of Buddhism From the Perspective of Culture-----Case Study of Chinese-English Translation in Wutai Mountain Tourism Attraction. Xinzhou Teachers University Journal, (3): 67-68.

[2] Chen Gang. (2014). Tourism Translation. Hangzhou: Zhejiang University Press.

[3] Chen Gang. (2014). Tourism Translation and Guide-Interpreting Studies. Beijing: China Translation \& Publishing Corporation.

[4] Chen Jinlian. (2015). A Genral Review of DomesticEco-translatology Studies Since 2001. Journal of Kunming University of Science and Technology ( Social Science Edition ), (2):86-93.

[5] Huang Dongqun. (2016). The Translation Study of Tourism Public Signs in Zhangzhou City From the Perspective of Eco-translatology. Journal of Zhangzhou Institute of Technology, (12): 36-40.

[6] Hu Gengshen. (2008). Of Translation Theory from Terms-----A General View of Translational Adaptive Selective Theory. Shanghai Journal of Translators, (2):1-5.

[7] Hu Gengshen. (2008). An Explanation of Eco-translatology. Chinese Translators Journal, (6): 11-15.

[8] Li Ertao. (2010). The Study of Standardizing English Translation of Shanxi Tourist Attractions and Publicity Materials. Journal of Shanxi Agricultural University (Society Science Edition), (5): 621-622.

[9] Liu Hongqing, Xu Jing, Su Peng. (2016). A Research on Key Issues of Chinese-English Translation With the Tousim Text of Yungang Grottoes as an Example. Journal of Higher Education, (14):256-257.

[10] Wang Yun. (2009). The English Translation of Cultural Information Buddhism Tourism Materials------The English Introduction of Wutai Mountain as an Example. Journal of Taiyuan Urban Vocational College, (12): 173-174.

[11] Yang Beiyi. (2018). The Translation Study of Tourism Public Signs From the Perspective of Eco-translatology. Journal of Changsha University, (4): 113-114.

[12] Zhu Yumin. (2015). The Characteristics and Translationof Public Signs in Tourist Attractions. Journal of Shandong University of Technology (Social Sciences Edition), (7): 67-69.

Zhaodong Zeng was born in Xinzhou, Shanxi province of China in 1995. He received his bachelor degree in English Teaching from Xinzhou Teachers University, China in 2017.

$\mathrm{He}$ is currently a graduate in the School of Foreign Languages, Shanxi Normal University, Linfen, China. His research interests include foreign linguistics and applied linguistics. 